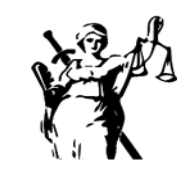

JUSTICIA

ISSN impreso 0124-7441
ISSN digital 2590-4566

\title{
Derecho a la resistencia y constitucionalismo: apuntes desde Gargarella
}

\section{Right to resistance and constitutionalism: notes from Gargarella}

\author{
(iD) \\ Camilo Andrés Maiguel Donado \\ Universidad del Atlántico, Colombia \\ cmaiguel@maial.uniatlantico.edu.co
}

\author{
iD \\ Jorge Mejía Turizo \\ Universidad del Atlántico, Colombia \\ mejiaturizo@gmail.com
}

\author{
(iD) \\ Elías Jacob Barrios Márquez \\ Universidad del Atlántico, Colombia \\ ejacobbarrios@mail.uniatlantico.edu.co
}

Recibido: 07 de noviembre de 2019 / Aceptado: 11 de marzo de 2020 https://doi.org/10.17081/just.25.38.4399

\begin{abstract}
Resumen
El presente artículo, pretende esbozar un análisis historiológico, iusfilosófico y sociológico de cómo las sociedades a lo largo de la historia han estado relacionadas a la lucha popular como medio de acción ante la cosmología que le acaece. Se inicia desde el punto del constitucionalismo como análisis desde Inglaterra, donde se comprueba que la lucha popular acompañó este momento de la historia, se aterriza en el pensamiento de Gargarella sobre el derecho a la resistencia y finalmente se hace una reflexión acerca de las realidades sociales contemporáneas. El diseño metodológico se encausó por el paradigma hermenéutico e histórico-crítico, con un método deductivo y enfoque cualitativo, apoyados en la técnica de análisis documental, sobre todo de fuentes bibliográficas específicas y generales sobre el derecho a la resistencia y sentencias de la Corte Constitucional. Como resultado, se obtiene que la lucha popular, siempre estuvo y estará presente en la historia para la redefinir y garantizar los derechos.
\end{abstract}

PALABRAS CLAVES: desobediencia civil, derechos, resistencia, sociedades emancipadoras.

Abstract

The present article tries to sketch a historiological, iusfilosófico and sociological analysis of how societies throughout history have been related to the popular struggle as a means of action against the cosmology that occurs. It begins from the point of constitutionalism as an analysis from England, where it is found that the popular struggle accompanied this moment in history, it lands on Gargarella's thinking about the right to resistance and finally a reflection is made about social realities contemporary. The methodological design was prosecuted by the hermeneutical and historical-critical paradigm, with a deductive method and qualitative approach, supported by the documentary analysis technique, especially from specific and general bibliographic sources on the right to resistance and judgments of the Constitutional Court. As a result, it is obtained that the popular struggle has always been and will be present in history to redefine and guarantee rights.

KEYWORDS: civil disobedience, emancipatory societies, rights, resistance.

\section{Como citar:}

Mejía Turizo, J., Maiguel Donado, C. A., \& Barrios Márquez, E. J. (2020). Derecho a la resistencia y constitucionalismo: apuntes desde Gargarella. Justicia, 25(38), 143-162. https://doi.org/10.17081/just.25.38.4399 


\section{Introducción}

La historia de la humanidad, siempre ha vivido permanentes estadios de convulsión social o confrontaciones bélicas por causas diversas. En la misma génesis histórica, emerge el noúmeno de un estado de supuesta fetichización de los hechos sociales y fenómenos físico naturales, que rodean la construcción de las causas eficientes de tales hechos y fenómenos en un plano de abstracción y superstición. Así pues, la evolución del hombre ha transcurrido entre una pendular o cíclica deconstrucción y reconstrucción, nacen en el mundo las antítesis, las tesis o en el mejor sentido de Marx, las críticas de las críticas-críticas. (Marx, K. \& Engels, F.,1975)

Parece ser que el ser humano, desde las concepciones antropológicas que lo sitúan en su relación epistemológica con los seres de la naturaleza, se ha estado arraigando dentro de este estado de rodeo en un movimiento historiológico pendular, donde fluctúan sus cosmovisiones entre los antropocentrismos radicales, relativos y alternativos, hasta la fetichización de objetos físicos y metafísicos para abstraerlos al plano de las meta-normas, y que derivan en la construcción de una historia para nada lineal.

El hombre en la antigüedad, bárbaro y con el grado de raciocinio que hasta entonces había adquirido, mirado desde la óptica de las concepciones sociales actuales, lo determinan como sujeto de análisis, Verbigracia, los estudiosos de Baudelaire, como (Bandy \& Pichois, 1957), dicen que "finalmente el hombre sometido a la naturaleza siempre me ha parecido que da un paso hacia la barbarie original" (p. 205). Se ha visto que se ha procurado siempre por la organización, pero dentro de esa misma se ha eregido la sensación de que siempre se vuelve a esa época de barbarie, delimitado por los hechos, las palabras y en general de todo el producto de un análisis serio desde la dialéctica bien dicha, recabada en métodos hermenéuticos de análisis estructural.

Es por lo dicho que, el análisis estructural de una situación a describir, desenlaza en un solo punto, la resistencia, la lucha popular, la evolución del diálogo social y el conflicto en general como medio de reacción ante las discordias sociales; pero de la resistencia, se hace muy confuso el diseño argumentativo, es por ello que se recurre a ciencias blandas como la sociología y la antropología para dar en el punto de explicación alrededor de la razón del ser de la relación conflicto-resistencia que siempre ha sido fórmula persistente en la historia.

Ahondando, de esta forma, se puede determinar que las bases epistemológicas e historiológicas, van indicando cuál es el camino a seguir por el derecho. El derecho como resistencia, de Roberto Gargarella, puede hacernos una idea, y es que aquí se legitima la resistencia y el derecho como aparatos de poder para la emancipación de los derechos. Los derechos fundamentales están llamados a trascender so pena de los aspectos situacionales que describen la discusión con los actores sociales. (Gargarella, R., 2003)

De esta forma, surge dentro del pensamiento jurídico en general, la posibilidad de resistirse al derecho, es decir, la desobediencia a la norma jurídica. Resulta un poco inocuo abordar una discusión que a la luz del positivismo parece superada, pero que a la luz del naturalismo parece situada dentro de un temario casi que obligado por la re-definición de los derechos. Lo que sí es cierto, es que en la contemporaneidad y la teoría del derecho que se le antepone, reconocen a la resistencia como un derecho inherente a la sociedad.

No solo entra dentro del asidero la posibilidad de encauzar un debate en torno a la eficacia de la norma en el mejor sentido Kelseniano, sino que parece que el debate nos lleva a un punto en el que la ciencia jurídica no agota su campo, cuando la discusión entra en un cross y termina por hacerse gaseosa o vaga. Lo que encierra a esa idea vaga dentro de una urna para hacerla visible, sin duda alguna va a ser la norma positiva, por eso se dice que termina el pensamiento jurídico por rondar en círculos, sin embargo, toma grosor 
dicho debate cuando la misma Corte Constitucional colombiana plantea: "si las personas deben obedecer sus leyes siempre y en todas las circunstancias o este deber de obediencia cesa y surge la obligación de la resistencia cuando la ley es injusta, o ilegitima (emana de quien no tiene el poder de legislar), o inválida (inconstitucional)." (Corte constitucional, 20008. Pg. 1)

Sin duda alguna, el principio pluralista de una nación puede terminar los arrojar hacia un solo punto el debate, en un sí (la sociedad tiene derecho a resistirse a la norma injusta), sin embargo, vale la pena preguntarse si ahí se acaba la discusión. De este modo, es aún más preciso aseverar que una sociedad que se enfrenta a un pluralismo como factor disyuntivo desde un punto de vista sociológico, cabe totalmente la discusión en torno al grado de eficacia de una normatividad. (Wolkmer, A. C., 2003)

"Los modelos culturales y normativos que justificaron el mundo, la organización social y los criterios científicos, se volvieron insatisfactorios y limitados, abriendo un espacio para repensar sociológicamente nuevas normas de refencia (sic) y legitimización. Transponiendo esto para lo socio-jurídico, se nos permite consignar que la estructura normativa del moderno Derecho positivo formal es poco eficaz y no consigue atender la competencia de las actuales sociedades periféricas, como las de América Latina, que pasan por distintas especies de reproducción del capital, por acentuadas contradicciones sociales y por flujos que reflejan crisis de legitimidad y de funcionamiento de la justicia." (Wolkmer, A. C., 2003., Pg. 2)

\section{Metodología.}

Para la construcción del presente artículo científico se utilizó la metodología de un paradigma hermenéutico, un método deductivo y un enfoque cualitativo, que se valió del análisis y síntesis en el estudio de fuentes bibliográficas específicas y generales sobre el derecho a la resistencia, las sentencias de la Corte Constitucional y los estados actuales socio-políticos de los Estados latinoamericanos. El paradigma hermenéutico orientó la interpretación de los datos colegidos y relacionados de manera material con la temática abordada.

El método que se tomó para el desarrollo es el histórico-crítico -puesto que permitió entender desde Inglaterra el proceso evolutivo del tema- mediante la elaboración del estado del arte sobre el derecho a la resistencia y la lucha popular en Inglaterra y Colombia. Para llevar a cabo dicho proceso, se consultaron fuentes oficiales de producciones legislativas y además se analizaron también normas internacionales que amparan este en el sistema internacional de los derechos humanos.

De igual forma fue útil la técnica de análisis documental puesto que mediante este se logró conseguir una adecuada recolección y sistematización de la información, dicho esto se pasó a constituir en un punto de enlace con toda la investigación que dio origen a la tesis de revisión, toda de postura y conclusión del presente artículo.

\section{Resultados:}

\section{Las peticiones populares en el constitucionalismo inglés a partir de la carta magna}

Desde los prolegómenos de la historia del mundo, se cuece siempre la organización social y estructural del Estado en aras de la obtención de la satisfacción de los factores reales de poder. Es por eso que el pueblo, desde tiempos inconcebibles en la memoria histórica, ha buscado la satisfacción de sus necesidades y junto a la tenue y lenta organización estatal ha conseguido grandes pactos sociales en pro de la comunidad en general o bien sea, a favor de ciertos sectores sociales. 
En el siglo XIII, se desarrollaba el sistema económico feudalista. En este sentido se enarbola la carta magna como un pacto entre los señores feudales (Barones) y el rey en ese entonces, Juan I. Los barones sublevados, exigían la garantía de ciertos derechos económicos que le acaecían debido al cambio de condiciones dadas por la pérdida de territorio en las colonias establecidas en la vieja Europa.

Así las cosas, la carta magna ha tenido diversas interpretaciones debido a su alto contenido normativo. Algunos la interpretan como una ley, so pretexto de la autoridad que la profirió, aunque esta vista entró rápidamente en desuso, sobre todo luego del incumplimiento de la misma carta y la generación de la I guerra de los barones; de otro lado, se encuentra una visión más acertada, catalogada como una concesión real, en forma de pacto colectivo de derecho público y declaratoria de derechos.

De este modo, la carta magna -históricamente- se ha establecido como producto de un gran pacto derivado del diálogo social en su sentido más incipiente, donde una aristocracia feudal con un señor territorial, al que siempre emerge su homenaje como contraprestación por los derechos garantizados. La eficacia política del modelo de esta carta magna descansa en una idea legendaria que ciertos partidos se formaron de ella y que, a día de hoy, se puede encontrar dentro del pensamiento jurídico constitucional.

A partir de estas aseveraciones, es preciso desentrañar la esencia de los derechos. Y es que no es tarea sencilla, prueba de ellos es que años de historia han devenido para llegar a afirmar que los derechos -en principio-son exigencias que el individuo puede reclamar y que devienen directamente de la interpretación principalista que se ha hecho para establecer una amalgama de mandatos de optimización y plasmarlos en un documento de declaración de derechos, actualmente figurante como constitución.

Y es precisamente de un somero estudio sociológico que se puede establecer la efectividad de estos mismos derechos, lo cual arroja un problema grande, debido a que pone de frente al jurista a panorama en que los derechos tendrán un diferente grado de efectividad en cada parte del mundo, y no siendo esto suficiente meollo para la configuración normativa, se tiene que en cada parte los derechos son distintos que en otras, o por lo menos a la hora de ponderar ciertos derechos con otros, el examen de sacrificio de derechos nos arrojare resultados muy equidistantes. No obsta lo anterior para poder explicar de dónde nacen entonces estas concesiones que el tirano, rey, monarca, etc. en cabeza del Estado accedía al pueblo. Es de conocimiento público que la historia se ha visto permeada de guerras y disyuntivas en situaciones de tensión y reclamos, debido a eso en ciertas ocasiones el rey necesitó del pueblo en la edad media para la obtención de ciertos fines del Estado, y esto desencadenaba un arreglo entre partes para la colaboración armónica. Para la clara ilustración, nos paramos de frente ante el contexto traído a colación anteriormente que derivó en la suscripción de la carta magna por parte de Juan I.

“En perspectiva, parece que el poder de Juan estuvo constantemente desafiado por tres poderes rivales: el del Rey de Francia, el de la Iglesia Católica y el de los barones ingleses. Y, en situaciones de debilidad, Juan no dudó en hacer a cada uno de ellos importantes concesiones, que luego no respetó. De hecho, en el origen de la Magna Carta está su lucha contra esos tres poderes." (Gil-Delgado, 2009. Pg. 2)

Estas concesiones explicadas, poco a poco se fueron convirtiendo en derechos básicos de las personas, cosa que desencadenó inminentemente la disminución potencial de los poderes del rey. Cada día el monarca necesitaba más de su pueblo, y este so pena de esta situación, exigía más garantías y se volvió costumbre pretender y exigir.

So pretexto de lo anterior, se puede hacer un recorrido por varios documentos primigenios de carácter constitucional que se erigieron teniendo como esencia dos cosas: 1) límite al poder soberano, 2) concesión de derechos al pueblo. 
Primero fue en 1215, la carta magna; en 1628, petitions of rights; en 1647, agreement of the people; en 1679, habeas corpus act; en 1689, bill of right; y en 1701, act of the seatlement. Hst finalizar esta etapa del constitucionalismo, en la primera declaración moderna de derechos en 1776 con la constitución de los Estados Unidos.

“... lo expuesto basta para manifestar su sentido general de una ordenación que invoca y se justifica en la tradición. De hecho, la interpretación prevaleciente, expuesta por ejemplo por un jurista liberal como Blackstone, en el siglo XVIII, es que la Magna Carta lo que hace es recuperar los principios del viejo derecho sajón, previo a los normandos, y dulcificar y atenuar el rigor del sistema feudal establecido por estos conquistadores." (Gil-Delgado, 2009. Pg. 9)

Esta esencia tradicional y restauradora desentrañable en la Carta Magna, no obsta para dejar en claro que esto supuso un gran avance en materia constitucional que, de hecho, algunos lo califican de revolucionaria, bajo el entendido de que nos encontramos ante una revolución antimonárquica de carácter nobiliario. A este fenómeno que se generó a partir de la promulgación de la Carta Magna, se le ha llamado muchas veces como constitucionalismo pactista, puesto que es un comportamiento socio-jurídico que se presentó de manera sistemática en el resto de documentos constitucionales posteriores a este compendio normativo.

(Kurland, P. B., Dunham Jr, W. H., Jennings, S. I., \& Thorne, S. E, 1966) ha dicho al respecto que "el papel que desempeñó la Magna Carta después de 1300 en la progresión del constitucionalismo inglés fue menor, pero bajo ningún concepto insignificante" (P. 253), frase que tiene su asiento bajo la tesis de que a pesar de que la Carta Magna no fue per sé una constitución, contribuyó para enarbolar dos principios fundamentales para el constitucionalismo: 1) Todo gobierno legítimo debe fundamentarse en un pacto social, 2) el concepto de la ley fundamental.

$\mathrm{Y}$ es precisamente de estos principios de donde deviene la pregunta problema que acaece este breve escrito: ¿Por qué las concesiones que se hicieron en la carta magna, se siguieron haciendo en el constitucionalismo inglés y sus demás documentos?

"La idea contractualista tiene su origen en la noción medieval de obligación política, que consistía en la fidelidad debida por los súbditos al Rey y que en Inglaterra se traducía en la obligación formal de prestar un juramento de fidelidad ("oath of allegiance") ante los tribunales locales. Esta exigencia tenía como contrapartida el juramento que el Rey debía hacer, en la ceremonia de su coronación, de proteger a sus súbditos y de conservar las leyes del Reino. Estas obligaciones recíprocas llevaban implícito una suerte de contrato, cuyo símbolo principal pasó a ser la Magna Carta, en la medida en que fue confirmada repetidamente por los sucesores de Juan Sin Tierra (al parecer, hasta cuarenta y cuatro veces entre 1216 y 1416)." (Gil-Delgado, 2009. Pg. 11)

Pero de la idea de ley fundamental es de donde se cuecen todos los prolegómenos de este aspecto esencial, puesto que raíz de la promulgación de esta carta, se hizo de orden principal y permanente el texto en el Inglaterra, hasta el punto de ser utilizado por muchos abogados en ejercicio y posteriormente fue confirmado por algunos otros textos como el statute Books por ejemplo; es decir en recopilaciones oficiales de leyes inglesas, y este mismo texto que se utiliza para la Carta Magna fue de uso común no solamente en escritos de fuerza legal positiva, sino también en la práctica judicial como parte del common law. Esto quiere decir que la Carta Magna se convirtió una fuente del derecho positivo y se incorporó en el acervo argumental del derecho inglés y en todo caso esto supuso la estabilización del Estado al ser confirmado un precepto escrito reiterativamente. 
A pesar de las deficiencias que presentaba la Carta Magna, precisamente fue por la confirmación de sus disposiciones en posteriores acuerdos que se convirtió en un asunto de vital importancia jurídica, política y social para las disputas populares, puesto que se centró esta lucha en factores reales de poder con alcances monárquicos y la disposición de aplicación del poderío, ligado a la capacidad de interpretación y control del ejercicio de todos estos tipos de prerrogativas consagradas.

Teniendo asi las cosas, las prerrogativas que fueron interpuestas en la Carta Magna se presentaron en posteriores escritos en el constitucionalismo inglés puesto que la Carta Magna constituyó un acto de Revolución monárquica y nobiliaria que se enalteció como ley fundamental y se basa primordialmente en principios de uso público y generalmente aceptados por la sociedad y por el derecho en aplicación de la regulación de la misma; demás de que era necesario teniendo en cuenta el contexto político que se desarrollaba en la época.

\section{Breve reflexión sobre la lucha popular en Colombia. Toma al palacio de justicia: Un retrato de dolor y lucha social.}

Colombia en el siglo XX, definitivamente fue un país de gran convulsión en cuanto a lucha popular y guerras civiles se trate - aunque en la región se ha mirado como uno de los más estables institucional y políticamente en siglo XX -. La historia mediata y más reciente de este país, ha estado marcada por el dolor, a la postre se ve la lucha por la justicia social y en aras del solsticio de una nación desesperada. Especialmente en los años 80', -una de las peores épocas de la violencia en nuestro país- Eb el cual se venía paralelamente cocinando, el sector insurgente de la lucha popular; el movimiento 19 de abril, que es de conocimiento público, M-19.

Errores como: ambición de poder, intemperancia de los dirigentes al debatir diferencias políticas y las injusticias políticas y sociales, como el estallido la pobreza y el decaimiento de la economía en el país, como fuente directa del desbalanceo en la justicia social, además del acompañamiento cumbre de los sectores de la "alta sociedad", que solo buscaban el beneficio personal y esto desplegaba la desigualdad. Todos estos gestores de una beligerancia por parte de un grupo guerrillero. (Navarro Wolff, A., 2015)

El M-19, principalmente centraba su lucha para ese entonces en que el gobierno nacional había incumplido su palabra de un pactado cese al fuego bilateral1; el expresidente Belisario Betancur, como máximo mandatario, se había comprometido a cesar el fuego en el intento por conseguir un acuerdo de paz. Además de ello, en ese entonces se encontraban sesionando los magistrados de la sala constitucional de la Corte Suprema de Justicia acerca de los asuntos relacionados con la extradición de narcotraficantes hacia los Estados Unidos. (Barrios Mendivil, R., 2015).

Ante los diversos sucesos ocurridos, el movimiento guerrillero, autor ya de otros simbólicos golpes como el robo de la espada de Bolivar, decide en un acto también simbólico por lo que significaba el centro de la justicia en Colombia y estratégico por el juicio y puesta en tela de pundonor al presidente, tomarse el Palacio de Justicia el 6 de noviembre de 1985. Le denominaron la Operación Antonio Nariño por los Derechos del Hombre. En la operación se mantuvieron cerca de 350 rehenes y se culminó 27 horas después dejando un saldo de 98 muertos, entre ellos 11 magistrados, y 6 desaparecidos a día de hoy.

Para dejar a la observancia de presente caso, la comisión interamericana de derechos humanos al conocer del mismo, lo calificó como una masacre y lo elevó al rango de holocausto, toda vez que se violaron

1 Véase, Acuerdos de Corinto, 24 agosto 1984. 
flagrante, abierta y sistemáticamente derechos humanos y normas del derecho internacional público y humanitario por parte de los dos bandos beligerantes, dejando así, saldos considerables de muertes y desapariciones de civiles y servidores públicos.

“Durante las 28 horas que transcurrieron entre el momento en que se inició la toma del M-19, hasta la recuperación total por parte de las Fuerzas Armadas, se presentó un auténtico golpe de Estado, pues el poder real y el manejo de la represión corrió por cuenta de los militares." (Vega, 2016. P. 5)

A propósito de las condiciones circunstanciales que rodean el hecho, se podría hacer una breve reseña conclusiva acerca de las verdades a medias que emergen como resultado de un hecho tan controversial como poco conocido realmente, sucedido hace más de 30 años.

Para los atrevidos operadores judiciales que se han tomado la valiente tarea de conocer los hechos, emerge la verdad judicial; y no es otra que la responsabilidad directa e indirecta por la cual responden altos mandos militares encargados de labores generales y específicas a lo largo del suceso. "En términos de verdad judicial el hecho más notable no se dio en el país sino afuera, con la condena que la Corte Interamericana de Derechos Humanos profirió contra el Estado colombiano el 14 de noviembre de 2014, "mediante la cual declaró responsable internacionalmente al Estado de Colombia por ciertas violaciones de derechos humanos cometidas en el marco de los sucesos conocidos como la toma y la retoma del Palacio de Justicia, en la ciudad de Bogotá, los días 6 y 7 de noviembre de 1985". (Vega, 2016. P. 16)

Aquí se responsabilizó al Estado colombiano por las desapariciones forzadas de Carlos Augusto Rodríguez Vera, Irma Franco Pineda, Cristina del Pilar Guarín Cortés, David Suspes Celis, Bernardo Beltrán Hernández, Héctor Jaime Beltrán Fuentes, Gloria Stella Lizarazo Figueroa, Luz Mary Portela León, Lucy Amparo Oviedo Bonilla y Gloria Anzola de Lanao y las desaparición y ejecución de Carlos Horacio Urán Rojas.

Además, cabe resaltar que la Corte Interamericana, señaló un acto completamente reprochable al Estado: "la Corte consideró demostrado que existió un modus operandi tendiente a la desaparición forzada de personas consideradas como sospechosas de participar en la toma del Palacio de Justicia o colaborar con el M-19. Los sospechosos eran separados de los demás rehenes, conducidos a instituciones militares, en algunos casos torturados, y su paradero posterior se desconocía" (Corte Interamericana de Derechos Humanos, 2014. Pg. 5)

A medida que el tiempo pasaba, los enfrentamientos entre el M-19 y los militares cada vez era más fuerte y el traslado de personas sin vida al Palacio de la Casa del Florero de Llorente (que sirvió como base militar) para su identificación también se hizo cada vez más notorio. No sé volvió a saber del paradero de muchos de ellos. Los heridos fueron llevados a clínicas y hospitales. Pero lo que marcaría el sesgo de la lucha popular reciente en Colombia, es que, ese mismo día, ningún canal de televisión o medio de comunicación alguno se dedicó a mostrar lo que sucedía durante la toma del Palacio de Justicia; ese mismo día, se enfrentaban Unión Magdalena y Millonarios, y dos horas después -cuando había terminado el partido de futbol- ya la tragedia del Palacio de Justicia era una realidad, ya el templo de la justicia en pocas horas, ardía por sus cuatro costados y muchas de personas inocentes ya habían muerto, como las esperanzas por conseguir una paz.

Entonces vale la pena preguntar, ¿es la desobediencia civil -so pretexto del derecho a la resistencia- el modelo a seguir? 


\section{El derecho a la resistencia en el pensamiento de Roberto Gargarella: Aproximación conceptual al derecho a la resistencia}

La historia del ser humano y la concepción del derecho más remota se han caracterizado por luchas constantes, por contradicciones tanto en el obrar fáctico como en el actuar jurídico, por órdenes legales establecidas y por la transgresión de los mismos cuando estos se tornan ilegítimos para el pueblo o para una población específica. Desde la cuna de la filosofía, pasando por el Derecho Romano, la Edad Media, el advenimiento del Estado Moderno con la Revolución Francesa, hasta el contemporáneo Estado social de derecho, la resistencia ha sido un común denominador a cada proceso de transformación.

De esta amalgama de hechos históricos, surge el llamado derecho de o a la resistencia para hacer frente al despotismo del poder. Por supuesto, cada época representó una concreción histórica de este derecho, permitiendo a los doctrinantes de hoy sentar las bases de un tema que para unos representa un problema en relación con el adecuado funcionamiento de determinado gobierno, mientras que, para otros, representa la obstinación de aquellos que se niegan a vivir sin la materialización de derechos constitucionales.

El concepto del derecho de o a la resistencia se ha tornado ambiguo debido a sus distintas manifestaciones en la historia. Se le ha considerado como institución propia del derecho natural; como fundamento del derecho positivo; como teoría política unida a otras desde una perspectiva genérica de la naturaleza del Estado y sus fundamentos; como un programa de acción. Esta pluralidad de enfoques hace que se dificulte la tarea de delimitar la formulación del derecho de o a la resistencia (Ugartemendia, 1999).

Sin embargo, muchos doctrinantes han arrojado luz y entre sus líneas se logra ver una constante: limitar el poder ilegítimo. (Llorente, $\mathrm{R}, 1975$ ) define al respecto:

“Tomando al derecho de resistencia como género, esto es, derecho de resistencia lato sensu, nos referiremos a la formulación histórica general que englobaría a una serie de conductas cuyo denominador común es el de implicar todas ellas un enfrentamiento con el poder «no sólo como enfrentamiento fáctico, sino también jurídico, como desconocimiento o negación de la pretensión de legitimidad del poder o de la justicia de su actuación" (p. 910).

El sentido lato de esta definición es preciso abordarla en todas sus dimensiones para transladar la discusión más alla de un plano excepcional. Si bien la regla general indica que el derecho de resistencia va dirigido a las conductas que se enfrentan a un poder considerado ilegítimo (puesto que actúa por fuera de los límites de lo justo), no es concebible una resistencia cuya manifestación sea injusta (tal es el caso de las resistencias criminales, desobediencia común, etc.) (Ugartemendia, 1999). Esto implica que el ejercicio del derecho de resistencia debe estar ajustado a derecho y en el respeto por la Constitución.

No obstante, este mismo podría quedar infundado si no existiera una norma que le facultara su accionar o si esa misma norma le otorgara legalmente facultades arbitrarias al titular del poder. Pese a esto, en sede de derechos humanos y en la prevalencia que ha adquirido la Constitución en los ordenamientos jurídicos, los límites y contrapesos que se le hacen al ejecutivo son propios de un Estado social de derecho. Por lo tanto, si hay alguna salvedad o requisito que deba cumplir el derecho de resistencia para adquirir legitimidad, la misma norma fundamental se lo otorga.

Al respecto, se dice que:"Será necesaria pues una distinción entre el titular del poder público y una norma concebida como suprema, limitante de los actos o disposiciones normativas de aquél. Dicho de otra forma, será necesaria una mínima contraposición normativa (ya sea entre ley y ley o entre ley y moral) para que el derecho de resistencia sea concebible no sólo como mera resistencia, sino como una acción legítima, 
esto es, como derecho" (Urgatemendia, 1999. p. 215).

Esa justificación del derecho de resistencia tendrá razón también siempre que el gobernante opere de manera ilegítima o atente contra principios generales del derecho. De esa manera, todo gobierno cuya instauración sea ilegítima (no democráctica) o que siendo legítima (democrática) devenga en un ejercicio arbitrario, dará lugar a que se autorice "la desobediencia civil y el uso de la fuerza con el fin de derrocarlos y reemplazarlos por gobiernos que posean legitimidad" (Otamendi, 1998).

En ese orden de ideas, puede señalarse que: "Un enfrentamiento (resistencia, desobediencia) que a la postre se torna en una limitación del poder de la autoridad pública; en este sentido, cabría conceptualizar el derecho de resistencia como el derecho del particular, o de grupos organizados, o de órganos del Estado, o de todo el pueblo, de oponerse con cualquier medio, incluso con la fuerza, a un poder ilegítimo o al ejercicio arbitrario y violento, no conforme al derecho, del poder estatal" (Cassandro, 1988. p. 995).

Frente a esta noción, se puede destacar que si lo que se pretende resistir es el poder ilegítimo no conforme al derecho, luego entonces, lo que se busca mantener o restituir es un poder o un estado de cosas ajustadas a derecho. Mario Bovero (1997) precisa al respecto al afirmar que "el derecho de resistencia, encontrará justificación en esa suprema norma, siendo configurado como el derecho que detentan los sometidos al poder público a preservar y/o restablecer el status que aquélla establezca" (p. 170).

La manera en que se entiende el derecho plantea, entonces, una doble vía en relación con su obediencia y los límites a la misma: "la de la posibilidad actual de resistir al y desde el derecho" (Olarte, 2011, p. 11). Resistir al derecho desde el derecho lleva implícita la necesidad de una norma jurídica que faculte tal transgresión. Es decir, el derecho de resistencia sí y sólo sí es justificado en la medida en que el poder público haya dejado de observar un precepto que le era obligatorio acatar. Por tanto, la violación de un precepto de obligatoria observancia justifica y legitima la existencia y el ejercicio de la resistencia (Ugartemendia, 1999, p.215).

Dicho todo esto, deben señalarse algunos puntos característicos del concepto del derecho de resistencia, a saber: primero, pretende limitar un poder ilegítimo que ha desacatado normas fundamentales y cuya violación raya en la esfera de la arbitrariedad. Segundo, su ejercicio debe estar ajustado a derecho y debe propender por el respeto de la Constitución. Tercero, este derecho se justifica en la medida en que se busque mantener o restituir el estado de cosas que la norma fundamental establece (Ugartemendia, 1999). Por último, representa la posibilidad de resistir al derecho desde el derecho.

\section{Derecho a la resistencia en el pensamiento liberal positivo.}

El constitucionalismo nato se caracterizó por instaurar en sus bases doctrinales al derecho de resistencia como un derecho privilegiado, que trascendía el límite de ser meramente un derecho para ubicarse en el plano de un deber. Este deber propio de los gobernados se activaba luego de que el poder político infringiera sistemáticamente sus obligaciones primarias (acceso al poder de manera ilegítima sin el consenso de los gobernados, transgresión de derechos inviolables y falta de protección de derechos inalienables de las personas).

Ahora bien, ese lugar de honor ocupado por el derecho de resistencia en la Declaración de la Independencia norteamericana, en la Declaración de los Derechos del Hombre francesa, o en buena parte de las Constituciones latinoamericanas del siglo XIX, ha perdido su importancia durante los últimos doscientos años (Gargarella, 2005). Es por esto que, estudiar el derecho de resistencia en el pensamiento liberal positivo suscita un debate en torno a su reconocimiento y a su efectividad. 
La concepción clásica de este derecho se gestó en la época precedente a la Revolución Francesa con postulados doctrinales y se consolidó hasta mediados del siglo XX ya con su consagración/normativización constitucional. A partir de la terminación de este periodo clásico hasta la contemporaneidad se plantea el carácter dominante de la perspectiva positiva liberal del derecho de resistencia (Pérez, 2016). El pensamiento liberal ha otorgado reconocimiento normativo al derecho de resistencia desde distintas perspectivas propias del pluralismo jurídico.

Siguiendo con (Pérez, 2016), son varios los contenidos que describen el periodo liberal de este derecho: 1. Sensu stricto o como derecho natural; 2. Como "forma ética de exteriorización de la conducta" (para efectos de una mayor precisión terminológica, se llamará forma moral y no ética) ; 3. Como "derecho fundamental"; 4. Como "expresión excepcional y proporcional" correspondiente a situaciones "extremas"; 5. Como "forma de control del poder político desde sí mismo" y; 6. Como "forma de salvaguarda y defensa del orden constitucional".

El primer contenido, aborda a la resistencia en su sentido estricto como un derecho natural (iusnaturalismo) innato al ser, caracterizada por ser subjetiva (propia del ser), contestataria pero no arbitraria. Representa la actitud manifiesta en medio de circunstancias adversas cuyo detonante son las constantes situaciones de injusticia social y opresión económica por parte del titular del poder político tirano y represor. De esta manera, el individuo entiende que su reacción consciente se haya facultada en la medida en que defiende su propia personalidad (la resistencia es innata al ser) en concordancia con una realidad institucional afectada (Pérez, 2016).

El segundo contenido, producto del anterior, entiende a la resistencia como forma moral de exteriorización de la conducta. Esto trae a colación el debate en relación con la moral y el derecho. Desde el punto de vista kelseniano, "el derecho puede ser moral, en el sentido de la justicia, pero no es necesario que lo sea" (Kelsen, 1982, p.76). Sin embargo, cuando bienes jurídicos tan invaluables como la vida o la libertad se ven coartados, la carga axiológica que esto representa para los afectados impone la necesidad de que el derecho sea justo.

Bajo esa óptica, el mismo Kelsen sustenta la concordancia que puede haber entre moral y derecho, pues ambos manifiestan carácter relativo, dado que el derecho se encuentra en permanente cambio, y que el orden jurídico o ciertas de sus normas, que en el tiempo gozaban de validez pudieron haber correspondido a las exigencias morales de ese momento, pueden hoy ser consideradas altamente inmorales; de igual modo, no se habla de una única moral, sino de muchos sistemas morales (Kelsen, 1982, p. 81). Dicho de otra manera, la moral como sistema obliga en determinadas circunstancias a que los gobernados exterioricen su conducta resistente frente al arbitrio del poder y, por tanto, se considere que concuerda legítimamente con el derecho.

El tercer contenido del pensamiento liberal entiende al derecho de resistencia como derecho fundamental en la medida en que se halle reconocido constitucionalmente. Esta caracterización tiene su génesis en los procesos revolucionarios propios de la Revolución Francesa (siglo XVIII) con el surgimiento del Estado Moderno y concluye en el siglo XX con la juridificación de este derecho. Lo que tiene mayor relevancia en este aspecto es considerar al derecho de resistencia en dos instancias, pero sobre todo en el marco del derecho, nunca como una idea extrajurídica.

La primera instancia se refiere a su dimensión formal, esto es, para que el derecho de resistencia tenga validez debe estar ligado a la constititución y, por tanto, respetar el principio de supremacía constitucional. La segunda instancia hace referencia a su dimensión material propia del los derechos subjetivos y que, par- 
tiendo de su consideracion consticional, va a devenir como un mecanismo de defensa, con lo que se ratifica su carácter fundamental (Pérez, 2016).

Esta limitación jurídica del derecho de resistencia hizo que su campo de acción fuera menos eficiente o más restringido, en la medida en que, la consagración de terías constitucionales como la de los frenos y contrapesos así como la instauración de distintos mecanismos de participación, hicieron que la estructura del Estado se robusteciera y, por consiguiente, el detentante del poder tuviera menos posibilidades de volverse tirano.

El paso de una democracia representativa a una democracia participativa no excluyó totalmente la representación. Ejemplo palpable de esto son los actuales mecanismos de participación ciudadana como la inicitiva legislativa, la acción pública de constitucionalidad, el sufragio universal, entre otros. Esto ha hecho cada vez más que el ejercicio del derecho de resistencia pierda su utilidad y efectividad.

El privilegio del que gozó en otros tiempos hoy se reduce simplemente a una necesidad. En principio llegó a considerársele como un derecho; más tarde, como un deber. No obstante y, curiosamente, ha sido su reconocimiento jurídico el que precisamente lo ha reducido a una simple necesidad o a un derecho secundario que, además, no puede ser tutelado, en los términos que plantea (Bobbio, 1991):

\begin{abstract}
"Jurídicamente, el derecho de resistencia es un derecho secundario del mismo modo que son normas secundarias las destinadas a la protección de normas primarias: es un derecho secundario que interviene en un segundo momento cuando son conculcados los derechos de libertad, de propiedad y de seguridad que son derechos primarios.
\end{abstract}

\title{
(...)
}

En la Declaración Universal de Derechos Humanos de 1948 se expresa: «si se quiere evitar que el hombre sea compelido al supremo recurso de la rebelión contra la tiranía y la opresión». Es como decir que la resistencia no es un derecho, sino, en determinadas circunstancias, una necesidad" (pp. 141-142).

Estas afirmaciones distan mucho de lo que las realidades en distintos países muestran: dictaduras disfrazadas de democracia, violación sistemática de derechos humanos, abuso de poder, fracturas en los órdenes institucionales $y$, por tanto, transgresiones por doquier de principios constitucionales. Es notable el peligro al que todavía se enfrentan los estados, pues las sociedades son cambiantes, no son uniformes. Esto implica que el significado moral del derecho de resistencia hace mella en el reconocimiento liberal positivo del mismo, y por ello, reducirlo a necesidad, a un carácter secundario no tutelable, resulta inviable en tiempos en los que todavía subsisten sistemas opresores.

El cuarto contenido lo fundamenta como "expresión excepcional y proporcional" correspondiente a situaciones "extremas", en las que el orden institucional y constitucional se enfrenta a situaciones de peligro inminente que ponen en riesgo la estabilidad y permanencia de los mismos. (Pérez, 2016) propone una serie de criterios que explican de manera detallada este contenido. Estos criterios van desde el plano fáctico hasta el puramente jurídico, de modo tal que, la resistencia se hará de manera proporcional al abuso del poder. Cuanto más aguda la opresión, así también la resistencia.

En primer lugar, está la opresión política que se manifiesta en el abuso de poder contrario al bien común, donde la opresión económica y social fungen como detonante de la resistencia social. En segundo lugar, la resistencia institucional que es aquella que recae sobre los funcionarios del poder público quienes en el ejercicio de sus cargos y responsabilidades administrativas están obligados a hacer contrapeso al 
gobernante. Por otro lado, la resistencia sociopolítica que se refiere a la oposición hecha mediante conductas cívicas sin el uso de la violencia (protesta pública, denuncia, desobediencia y mediación) originadas, de manera legítima, por el sistema político y la sociedad en general (partidos políticos, gremios, grupos, etc.). Por último, la resistencia legal caracterizada por el ámbito jurídico formal en el que se desarrolla, obliga a que la actuación de los gobernados sea estrictamente legal (vía judicial) con el fin anular el poder tiránico y restablecer el estado de cosas violentadas, incluso en aquellos ámbitos en que desconoce el principio de confianza legitima. (León, 2016)

Los límites establecidos en este contenido van a estar marcados en el plano de los derechos que con la resistencia se pretendan salvaguardad, por lo que, es obligatorio observarlos y respetarlos. Además, la resistencia se circunscribe en un plano excepcional, en el que de llegarse a presentar la no disponibilidad de medios sociales o jurídicos para la defensa del orden constitucional, entonces, el uso de la fuerza será entendido como el recurso idóneo caracterizado por ser de ultima ratio (que excluirá de responsabilidad penal a los que lo ejerzan). Así las cosas, tanto la situación negativa u opresora como el medio efectivo para su resistencia, deberán ser objeto del examen de proporcionalidad que se surtirá para definir su validez (Pérez, 2016).

El quinto contenido fundamenta el derecho de resistencia como "forma de control del poder político desde sí mismo". El Estado es considerado como una persona jurídica especial en sí mismo, cuya atribución principal es la de ejercer el monopolio de la coacción física legítima (Pérez, 1997, p. 67) así como la de tener cierta liberalidad en sus decisiones. Este obrar estatal es controlado por el derecho de resistencia para evitar que existan abusos o conductas anómalas en sus atribuciones. Esta óptica parte de la llamada "razonabilidad de la justicia" (Rawls, 1979) según la cual surge una respuesta ante el posible arbitrio de la institucionalidad.

El sexto y último contenido de la perspectiva liberal enfoca al derecho de resistencia como "forma de salvaguarda y defensa del orden constitucional". Este criterio sintetiza y cierra la esfera plural del derecho de resistencia y, además, ratifica la formulación jerárquica en el campo de los derechos fundamentales. En ese sentido, se recogen los criterios antes examinados: la defensa de un orden constitucional que ha sido transgredido por el titular del poder, cuyo objetivo es prevenir-impedir-restaurar la violación del mismo; el derecho de resistencia es reconocido positivamente como un recurso de ultima ratio en la medida en que todos los demás mecanismos de defensa resulten desproporcionales o ineficaces a los daños sistemáticos generados por el opresor (Pérez, 2016).

En igual sentido ha apuntado Carl Schmitt al expresar que todo ciudadado en determinadas circunstancias puede ser "considerado como un eventual protector de la Constitución", lo que, a su vez, le permite fungir como "una extrema garantía" (Schmitt, 1983, pp. 55-56). Asmimismo, Ronald Dworkin establece que existe una directriz a seguir cuando se hace uso de las distintas formas que materializan el derecho, esto es: restablecler los demás derechos y los fines estatales puestos en peligro. La resistencia es una conducta que se vuelve legítima desde el obrar de la consciencia y, en consencuencia, el derecho no debe castigarla (Dworkin, 1984, pp. 276 y ss.).

El papel dominante del pensamiento liberal positivo ha permitido establecer que los signos, absolutos e indispensables del derecho de resistencia -así como del resto de derechos de índole fundamental- serán su personalismo, su universalidad, su irrenunciabilidad, su imprescriptibilidad, su inviolabilidad y su orientación inalienable pero, con mayor atención, en su excepcionalidad. Tanto el concepto como la regulación normativa deben ir de la mano en el ámbito del reconocimiento, pues la segunda limita al primero: el derecho de resistencia se dirige a la conservación, defensa o restablecimiento del orgen jurídico y constitucional; no es arbitrario (Pérez, 2016). 
La resistencia como cualidad intrínseca al ser humano desarrolla su personalidad y la concretiza al hacerse visible en la sociedad como conducta que se opone a la opresión del poder. Y si se considera como tal, es imprescindible que la tutela de este derecho se haga efectiva y que, por tanto, se retome la idea de deber que en sus prolegómenos planteó este derecho contestatario. Todavía más, en los términos de Carl Schmitt el derecho de resistencia desde una interpreación histórica se ha constituido como una garantía en sí mismo. Su activación o justiticación surge a causa de las circunstancias sistemáticas transgresoras producidas por quien detenta el poder devenido en tirano. Así pues, es sustentable la resistencia como idea de derecho-deber-garantía que ha de ser jurídica y materialmente tutelado. Los postulados axiológicos del iusnaturalismo propios de la concepción clásica de este derecho siguen siendo las bases que han permitido su evolución hasta la modernidad, a pesar de la paradoja que ha supuesto su reconocimiento jurídico.

\section{Ahondando en Roberto Gargarella}

En la contemporaneidad, mayoritariamente en los Estados la idea de resistir y hacer frente de forma legítima a las injusticias por parte de un gobierno, a través de la no-cooperación y (o) confrontación con el mismo, parece haberse convertido en algo casi imposible. Esto a razón de que, la justificación con la cual la resistencia se hace defendible y deja de ser solo rebeldía, poco a poco ha sido desacreditada por la creación de figuras jurídicas que pretenden (por lo menos en el papel) resolver las inconformidades de los gobernados con respecto a sus gobernantes. Lo que en principio no tiene por qué ir en contra del derecho de resistencia, pero infortunadamente sí lo hace, al punto de haber llegado a apartar la resistencia de cualquier concepción relacionada con el derecho casi como si estos términos fueran contrarios entre sí.

Por tales motivos, es imprescindible abordar el desarrollo que el jurista y escritor argentino Roberto Gargarella ha planteado de manera estructurada en esta materia a través de sus distintos trabajos académicos. En primer lugar, Gargarella concibe al derecho de resistencia como un "derecho perdido" en la medida que, si bien estuvo durante mucho tiempo siendo un derecho de orden central, en la actualidad, parece ser menos factible, y además menos interesante o valioso que hace siglos (Gargarella, 2007). Esto se ha dado fundamentalmente por todos los cambios políticos que se han llevado a cabo a partir de la aparición del Estado Moderno.

Gargarella retoma la idea marxista consistente en que el derecho es un instrumento de dominación, cuya esencia es la ideología que hace aparecer naturalmente un estado de cosas opresoras. De esta forma, el poder que ostenta el titular le permite hacer funcionar la explotación de clases propia de los sistemas capitalistas (Ariza, 2009). Gargarella (Gargarella, 2005, pp. 19-20) acuña el concepto de "alineación legal" refiriéndose al cúmulo de situaciones en las que "el derecho comenzó a servir propósitos contrarios a aquellos que, finalmente, justificaban su existencias", por lo cual, "la resistencia resultaba defendible".

La descentralización del poder y la fragmentación social han contribuido respectivamente a el desconocimiento en relación con los responsables de la alineación legal, es decir, de aquellas situaciones en las cuales los gobernantes usan sus poderes en contra de los intereses del pueblo al que deben servir (Suárez, 1944); y la imposibilidad de la resistencia para ser cada vez más concebible, puesto que, en la mayoría de los casos un hecho denominado "injusto" no afecta a toda la población, sino solamente a una parte ella. Esto hace que, quienes no se ven afectados hagan todo lo posible para impedir la desestabilización de esa misma situación que en principio los favorece o no los perjudica (Gargarella, 2007).

Gargarella plantea, además, que esta desaparición paulatina del derecho de resistencia, es consecuencia de la propia organización institucional actual que incluye entre otras novedades la división del poder 
en distintas ramas, así como sistemas de "frenos y contrapesos", los que, en este sentido, reducen el riesgo de que el derecho se convierta en un instrumento opresivo. Esto sin contar las numerosas herramientas destinadas a facilitar o promover, de modo pacífico y ordenado, cambios políticos en el sistema.

Pese a lo anterior, Gargarella hace énfasis en que, aunque las herramientas sean muchas y la alineación legal pretenda ser eliminada, siempre que se afecte un derecho fundamental de todo ciudadano, la resistencia será necesaria. Y es que, existencia no equivale todas las veces a efectividad, porque aun con todas las garantías, existen sectores de la sociedad que día a día se ven afectados por un mal manejo del gobierno que, en primera instancia fue elegido para defender los intereses del pueblo.

En ese orden de ideas, Gargarella al citar a John Rawls plantea que emplear el aparato coercitivo del Estado con el objeto de mantener instituciones manifiestamente injustas constituye, de por sí, un uso ilegitimo de la fuerza que las personas en su debido curso tienen el derecho de resistir (Rawls, 1971). Mostrando de esta forma que bajo esos presupuestos la resistencia sigue existiendo y está además totalmente justificada. Ahora bien, pese a tener una justificación, se vuelve ilegítima por una serie de situaciones que esboza Gargarella, a saber: cuando la defensa de los derechos de un sector, menoscaba en gran medida los derechos de otro; o cuando, con excusa en la resistencia, se incumplen deberes que no afectan directamente su integridad. Esto resquebraja totalmente aquello que Gargarella llama "vinculo o nexo", esto es, aquel aspecto de la justificación que permite que un grupo resistente se abstenga de realizar acciones o cumplir obligaciones que afecten significativa y efectivamente sus derechos.

El pensamiento de Gargarella adquiere una connotación de mayor aplicación en los contextos de carencia extrema marginados (no representados, agredidos, olvidados) por el Estado, puesto que, en palabras del mismo autor: "no tienen un deber general de obedecer el derecho, dado que el orden legal no les ha asegurado la protección que necesitaban contra los daños mas severos que sufrían, a la vez que ha sido en parte responsable de la imposición de algunos de esos severos daños. En la medida en que el derecho se encuentra causal y moralmente implicado en su sufrimiento, ciertas formas de resistencia al derccho deberian ser vistas, en principio, como moralmente permisibles" (Gargarella, 2005, p.37).

Estos escenarios plantean serios debates en torno a cuestionamientos como los que el mismo Gargarella intenta resolver: ¿qué formas de resistencia deberíamos considerar aceptables?, ¿en qué medida podría justificarse la delincuencia? Frente a lo primero, se distinguen dos tipos de resistencia: resistencia pasiva o no-cooperación y resistencia activa o confrontación (señaladas al principio de este apartado). La resistencia pasiva se da en términos de omisiones a lo que el Estado estipula debe acatarse (negativa a pagar impuestos, etc.). La resistencia activa implica aquellas acciones destinadas a cuestionar o controvertir prohibiciones legales (ocupar tierras vacías, usar propiedades en desuso con el objeto de asegurarse y asegurarle a sus familias ciertos derechos básicos, etc.) (Gargarella, 2005). Agregariamos que la protestas, manifestaciones y movilizaciones son formas de esta resistencia activa, que en colombia se intentará regular mediante ley ( Congreso de Colombia, Proyecto de ley No 281 de 2019)

Frente a lo segundo, no existe claridad, pero implícitamente podría decirse que la delincuencia por razones económicas tendría un carácter político y, bajo esa óptica, habría que distinguirse entre delincuente político (que actúa contra un orden considerado ilegítimo) y delincuente común (que en términos weberianos actuaría guiado por la consecución de sus propios intereses) (Ariza, 2009, p. 103).

En síntesis, el pensamiento de Gargarella no es arbitrario ni tibio. Pretende ser coherente con la observancia de todos los escenarios posibles y las partes directa e indirectamente involucradas, puesto que, la resistencia tiene necesariamente una connotación social (a pesar de que esta se exteriorice, en ocasiones, 
por minorías). Es por ello que, Gargarella concluye su tesis afirmando varios puntos nodales:

1. No podemos fijarnos solamente en los reclamos particulares de quienes protestan sin tener en cuenta lo que tales protestas per se dicen acerca del sistema institucional dentro del cual ellas ocurren.

2. El derecho no puede observarse únicamente desde las mayorías o desde los ciudadanos bien integrados, sino también desde el prisma de los más desventajados (esto se refiere a la propuesta hecha por John Rawls). 3. No se pueden pasar por alto los valores o intereses legítimos que hay en juego en las protestas aun cuando las motivaciones de muchos de sus líderes sean egoístas, debido a la afectación sistemática propiciada por el Estado.

El derecho de resistencia, entonces, no deja de ser polémico, criticado y desarrollado por la doctrina. Situaciones violatorias de derechos humanos como la pobreza -según lo esbozaba Gargarella-, obligan a que el derecho de resistencia se haga materialmente efectivo, pues, si bien el ideal del Estado Social de Derecho es propender por la dignidad humana (sustancialmente hablando) en conjunto con los mecanismos jurídicamente idóneos para materializarla (procedimentalmente hablando), no ha sido suficiente para lograr tal fin. Se hace imprescindible concebir el derecho de resistencia en los términos sintetizados por Gargarella, considerando sus justificaciones y limitaciones a merced de las mayorías, pero también de los más desfavorecidos.

\section{Toma de postura}

Como bien se ha demostrado, Colombia -y en general Latinoamérica- vive en un constante estado de crisis en materia de derechos fundamentales. Lo anterior lo legitima, en términos del derecho penal del enemigo, la represión punitiva del castigo estatal; sin embargo, los Estados contemporáneos, poco caso parece hacer a los presupuestos del derecho liberal y únicamente se jactan de delimitar formalmente las garantías sin materializarlas, lo que a la postre arroja una situación, más que problemática, lamentable.

La legitimación para desobedecer el derecho, siempre se ha tratado en la teoría jurídica con especial atención, pero llega la hora de dejar de abstraer el pensamiento y comenzar a pensar si hay un estado de crisis o no. Se dice que a ley debe obedecerse, o por miedo al castigo, o por una actividad de reflexión interna que termina en un acto volitivo deliberado producto de una buena acción al sopesar la ley y el deber ser. No obstante, la restricción de la obediencia a la ley no puede ser permeada de ideales.

La obediencia a la ley, sin embargo, tiene una trascendencia mucho más profunda de lo práctico que se ha planteado a lo largo de la historia. La conducta que describe la ley en general y pretende -mediante el castigo o la inducción- su cumplimiento u omisión, per sé trasciende el pensamiento y la ideología, por lo que se ha hecho mella en que el derecho solo puede ser establecido democráticamente. Recoger las conductas y ceñirlas a una idea contractualista, no termina por convencer en la practicidad.

“Para Plamenatz la obediencia se predica del sistema en general, siempre, eso sí, que se den determinadas condiciones, consistentes en la existencia de medios legales al alcance para poder cambiar el sistema y defender el cambio. La obediencia que reclaman los sistemas democráticos sólo cede, según esta creencia, cuando se violan las formas básicas del sistema mismo" (Falcón, 2002. Pg. 101) 


\section{Una democracia contemporánea debe ser capaz de soportar la desobediencia civil}

Se parte entonces de la premisa que un Estado que goce de una cláusula social, debe ser capaz de reconocer la desobediencia civil como uno de los lastres de la democracia misma en reconocimiento del pluralismo. Parte de esto, nace no solo en las concepciones que propenden por la aceptación de una diversidad de criterios, sino que máxime, debe propender por la estabilización en general de una democracia que procura por la defensa de la ley del más débil en perjuicio de las organizaciones de poder.

Al respecto, se dice que estas democracias que no soportan la desobediencia civil, son en el fondo un Estado dictatorial vestido de democrático para los intereses de una constitución elitista. "Practicada a gran escala, la desobediencia civil podría desestabilizar un régimen no democrático, porque si el clima de desobediencia se va extendiendo, dicho régimen no tiene más que dos opciones a largo plazo: la supresión o la responsabilidad. Si sigue la segunda de estas vías el régimen totalitario estaría abierto a la posibilidad de un cambio real en la estructura del sistema, que evolucionaría hacia formas más abiertas y plurales de gobierno. Si no, la represión de los desobedientes sería brutal." (Falcón, 2002. Pg. 104)

Pero de la caracterización de las democracias liberales es de donde emerge la pregunta problemática en cuestión: ¿puede un Estado legislar para las minorías? ¿Existe ley formal del más débil? La cuestión pareciera que se adentrara en el plano filosófico de la teoría jurídica, pero la respuesta es mucho más sencilla de lo que parece; la representación ideológica de una abstracción problemática de una situación fáctica que acaece a un contexto social-democrático siempre va a generar un conflicto que intentará resolverse.

Prima facie, las minorías parece que, mediante mecanismos de desobediencia civil legitimada en el derecho a la resistencia, pusieran en jaque todo un orden constitucional democrático, pero suele pensarse que esto en principio sería un atentado general contra los principios de la misma. Sin embargo, esta resistencia es igual de útil y necesaria que un voto popular y aunque cree alguna contingencia de carácter transitorio, no debilitará un sistema; una democracia que es capaz de reconocer la resistencia y coexistir con esta, siempre será una democracia; en cambio, un gobierno que trate de reprimirla y acallar, solo dejará al desnudo su faceta autoritaria represiva y su alta incapacidad de gobernabilidad. (Buelvas y Florez, 2017) .

\section{Discusiones y conclusiones}

Ampliamente se ha sentado una discusión sencilla y a veces hasta baladí. La lucha popular, per sé. El abordaje historiológico e iusfilosófico que trató de delimitarse en el presente escrito, concreta la sustancialidad de la discusión en un sentido de extrema necesidad de la resistencia como base de toda sociedad. El pluralismo que un mismo gobierno puede utilizar para la consecución de adeptos políticos, es el mismo que luego le juega en contra y plantea un debate que muchos gobiernos son incapaces de llevar, pero que no se olviden las democracias liberales contemporáneas que el orden se construye a partir del conflicto.

“Jhon Rawls propuso que la desobediencia civil es algo más que un acto ilegal, público y no violento, dirigido a provocar un cambio en la legislación o en la conducta gubernamental; es ante todo un acto dirigido y justificado por principios políticos, es decir por principios de justicia que regulan la Constitución y en general las instituciones sociales... no apelamos a principios de moralidad personal o a doctrinas religiosas... sino que invocamos la concepción de justicia comúnmente compartida, que subyace bajo el orden político"(Corte Constitucional, 2008. Pg 2-3)

Todo lo dicho, permite establecer a manera de conclusión preliminar que, sin duda alguna, un derecho a la resistencia debe ser concebido en un Estado contemporáneo de manera no violenta, utilizando los 
mecanismos formales y materiales para el reproche social que ampliamente han funcionado y despojarse de la visión positivista de que la norma per sé establece un mandato imperativo y categórico que si no es cumplido acaecen consecuencias indefectibles en contra del autor.

De segunda forma, el derecho a la resistencia debe propugnar siempre por el establecimiento y defensa de un orden constitucional. Sin duda alguna el conflicto del que se ha hablado, no representa los conflictos habidos en la vida social del interés, el poder o la conveniencia política; el conflicto -eminentemente jurídico- de la resistencia surge de un plano valorativo formal que termina por establecer un debate iusfilosófico y axiológico en torno a la norma legal, válida, eficaz y eficiente.

Sobre el primer punto ha procurado pronunciarse la honorable Corte Constitucional (2008) "cabe señalar que el desobediente civil debe abstenerse de realizar cualquier lesión en las personas o menoscabo de sus derechos, así como de hacer daño a las cosas" (Pg. 2). Esto termina por establecer un marco de legitimación indebida, donde se puede sentar la premisa conclusiva de que una persona -que en aras de "reestablecer su democracia"- emprenda acciones igual, más o cercanas a lo violentas que son las que señala, no merece legitimidad.

De otro lado, sobre lo señalado, se permite hacer mella, en cuanto a que las manifestaciones externas del pueblo sean de no subsumirse a la norma jurídica vigente, pero estas mismas gozan de una dimensión valorativa de ilegalidad, esta misma sociedad -por su condición dentro del contrato social- deben guardar mínimamente el respecto por el orden constitucional e institucionalmente establecido, pues el respeto por la legalidad es lo que enmarca al ciudadano dentro de sus derechos reales y personales.

De este mismo modo, (la Corte Constitucional, 2008) "esa lealtad debe cifrarse en la aceptación de que el cambio de política o de sociedad que se propugna ha de obtenerse a través del consentimiento de la mayoría, no mediante la imposición" (Pg. 2), lo cual termina por traducirse en un estado de respeto por las mayorías y la democracia per sé. Y ya inmersos en este punto de la disertación, vale la pena establecer como conclusiones dos premisas que orientarán lo que se ha querido transmitir de esta manera.

De primer plano, vale establecer que la resistencia -sobrellevada por la desobediencia civil- se constituyen como mecanismos sociales totalmente legítimos en el marco de una democracia pluralista, participativa, dignas de un Estado Social de Derecho. La resistencia busca la preservación de los derechos fundamentales que se ven inminentemente lesionados por el mismo Estado el su afán de deliberación propositiva que solo determina en regresión de derechos y de su orden constitucional.

La misma tesis es apoyada por (Magoja, 2016), quien señala que: “El Estado Constitucional de Derecho, más allá de su valor, debe perfeccionarse, adecuarse a la realidad cambiante de la sociedad y aspirar a satisfacer los intereses de todos los involucrados en la empresa común. En esta tarea, el derecho de resistencia como genus juega un papel clave.", de lo que se dirime que el Estado, en sentido mancomunado con la población, debe aunar esfuerzos por la progresión constante de los derechos de los mismos.

De segunda medida, vale la pena citar a (Gargarella, 2007), quien señalaba que "era importante mantener a los ciudadanos activamente involucrados en la vida pública (en lugar de desalentarlos a través de la imposición de penas)" (Pg. 26), de donde se puede denotar la necesidad de una resistencia y el derecho formal aunado a esta, como bases de una fortaleza democrática de un Estado que goce de un orden constitucional robusto y que propenda por la promoción y garantía de los derechos de sus ciudadanos.

Así mismo, "era necesario mantener al gobierno bajo criticas permanentes; y era crucial, también, que los representantes sintieran el peso de la responsabilidad que estaba a su cargo. Por supuesto, no es fácil 
seguir a autores como los citados en sus discusiones sobre los límites del derecho. Por un lado, es esperable que, en las situaciones más graves, aquellas en donde prima la alienación legal, las condiciones sean las menos apropiadas para la deliberación individual y colectiva -dada la carencia de foros colectivos apropiados, dada la forma en que el dinero y el poder político pueden interferir con una comunicación pública transparente." (Gargarella, R., 2007. Pg. 27)

Lo robusto de una democracia va a garantizar el cumplimiento cabal de las garantías constitucionales, por eso, verbigracia de lo escueto, “como advierte Vitale, más allá de todas las garantías que ofrecen sustento y protección al sistema constitucional contemporáneo, el peligro de su violación no deja de evidenciar el riesgo latente de una fractura institucional profunda. Sobre este criterio reconoce, en primer lugar, la legitimidad moral del uso del derecho de resistencia y, más esencialmente, el significado de que, con su

reconocimiento, se estaría añadiendo un mecanismo adicional de protección a la Constitución, validez y continuidad, frente a cualquier intento de subvertirla" (Pérez, L., 2016. Pg. 12)

\section{Referencias.}

Ariza, L. J. (2009). Reseña de Gargarella, Roberto (2008). De la injusticia penal a la justicia social. Bogotá: Universidad de Los Andes-Siglo del Hombre Editores. Sortuz. Oñati Journal of Emergent Socio-legal Studies, Volume 3, 101-107.

Bandy, W. T. \& Pichois, C. (1957) Un souvenir de Verlaine.

Barrios Mendivil, R. (2015). La responsabilidad de Belisario Betancur en los hechos del Palacio de Justicia. Obtenido de www.colectivodeabogados.org: http://www.colectivodeabogados.org/cajar_old/spip. php?article6653

Bobbio, N. (1991). El tiempo de los derechos. Madrid: Editorial Sistema.

Bovero, M. (1997). Diritto di Resistenza. Milan: Modelli Analitici e Riflessioni Tcoriche.

Buelvas Mendoza, M., \& Florez Campo, O. (2017). Elementos para la discusión sobre la gobernanza y gobernabilidad en el posconflicto en Colombia. Erg@omnes, 9(1), 145-168. https://doi.org/10.22519/22157379.1016

Cassandro, G. (1988). Resistenza Volumen XXXIX. Milan: Enciclopedia del Diritto.

Corte Constitucional. (2008) Sentencia T-571-08. Mg. Ponente Humberto Antonio Sierra Porto.

Corte Interamericana de Derechos Humanos. (2014) Sentencia 14 de noviembre de 2014. Resumen publicado en El Espectador, noviembre 1 de 2014, p. 5.

Congreso de la Republica de Colombia, Proyecto de ley Estatutaria Num. 281 de 2019

Dworkin, R. (1984). Los derechos en serio. Barcelona: Editorial Ariel.

El Espectador. (2014). “Corte Interamericana de Derechos Humanos, Sentencia 14 de noviembre de 2014”. El Espectador.

Falcón, M. J. (2002). La obligación política de obediencia del individuo. Revista de estudios políticos, (115), 99-110.

Gargarella, R. (2003). La última carta. El derecho de resistencia en situaciones de alienación legal.

Gargarella, R. (2005). El derecho de resistir al derecho. Buenos Aires: Miño y Dávila.

Gargarella, R. (2005). La alineación legal y la justificación del derecho de resistencia. En R. Gargarella, El derecho de resistrir al derecho (págs. 13-48). Buenos Aires: Miño y Dávila .

Gargarella, R. (2007) El derecho de resistencia en situaciones de carencia extrema. Astrolabio. Revista internacional de filosofía. Núm. 4. ISSN 1699-7549 
Gil-Delgado, M. (2009) La magna carta: Realidad y mito del constitucionalismo pactista medieval. Historia Constitucional, n. 10, 2009. http://www.historiaconstitucional.com, págs. 243-262

Gómez, J. A., Herrera, J. R., \& Pinilla, N. (2010). Informe final. la Corte Constitucional de la Verdad sobre los hechos del Palacio de Justicia. Bogotá: Universidad del Rosario.

Kelsen, H. (1982). Teoría pura del derecho . México, D.F. : Universidad Nacional Autónoma de México.

Kurland, P. B., Dunham Jr, W. H., Jennings, S. I., \& Thorne, S. E. (1966). The Great Charter: Four Essays on Magna Carta and the History of our Liberty.

León García, M. V. (2016). El debate jurídico entorno a la tensión del principio de confianza legítima y la prevalencia del interés general. Erg@omnes, 8(1), 83-93. https://doi.org/10.22519/22157379.784

Lipman, M. (1990). Investigación social. Madrid: Ediciones de la Torre.

Magoja, E. E., (2016). La justificación del Derecho de Resistencia en el Estado Constitucional Democrático de Derecho: algunas reflexiones iusfilosóficas. Nómadas. Critical Journal of Social and Juridical Sciences, 47(1), .[fecha de Consulta 3 de Junio de 2020]. ISSN: 1578-6730. Disponible en: https://www.redalyc. org/articulo.oa?id=181/18153280003

Marx, K., \& Engels, F. (1975). Marx \& Engels Collected Works Vol 01: Marx: 1835-1843. Lawrence \& Wishart.

Navarro Wolff, A. (2015). "El peor error de la historia del M-19". El Tiempo.

Olarte Olarte, M. C. (2011). Prefacio: El derecho como transgresión, respuesta y obstinación. En P. Fitzpatrick, El derecho como resistencia : modernismo, imperialismo, legalismo (págs. 11-16). Bogotá: Siglo del hombre.

Otamendi, M. (1998). Democracia y Anarquía Tomo I. México DF: Ediciones Univisa.

Pérez Llody, L. A. (2016). La resistencia política como derecho fundamental. Reflexiones a propósito de los cien años de la Constitución mexicana. Revista IUS, 10(38) Recuperado en 03 de junio de 2020, de http://www.scielo.org.mx/scielo.php?script=sci_arttext\&pid=S1870-21472016000200004\&lng=es\&tlng=es.

Pérez Royo, J. (1997). Curso de Derecho Constitucional. Madrid: Marcial Pons.

Rawls, J. (1979). Teoría de la justicia. México: Fondo de cultura económica.

Rubio Llorente, F. (1975). La doctrina del derecho de resistencia frente al poder injusto y el concepto de Constitución. Caracas.

Schmitt, C. (1983). La defensa de la Constitución. Estudio acerca de las diversas especies y posibilidades de salvaguardia de la Constitución. Madrid: Tecnos.

Suárez, F. (1944). Selections from Three Works. Oxford: Clarendon Press.

Ugartemendia Eceizabarrena, J. I. (1999). El derecho de resistencia y su constitucionalización. Revista de Estudios Políticos (Nueva Época). Núm. 103, 213-245.

Vega Cantor, R.(2016). La masacre del palacio de justicia. Ejemplo emblemático del terrorismo de estado en Colombia (6-7 de noviembre de 1985). El Ágora USB, 16(1), 107-133. https://doi.org/10.21500/16578031.2168

Wolkmer, A. C. (2003). Pluralismo jurídico: nuevo marco emancipatorio en América Latina. M. Villegas, \& C. Rodríguez, Derecho y sociedad en América Latina: Un debate sobre los estudios jurídico críticos, 247-259. 
